\title{
The U.S. Geological Survey Amphibian Research and Monitoring Initiative-2011 Annual Update
}

\section{Objective}

The Amphibian Research and Monitoring Initiative (ARMI) assists Department of the Interior (DOI) resource management agencies with information needs related to amphibian conservation. This includes research addressing threats, method development, and monitoring designed to address management needs at multiple scales.

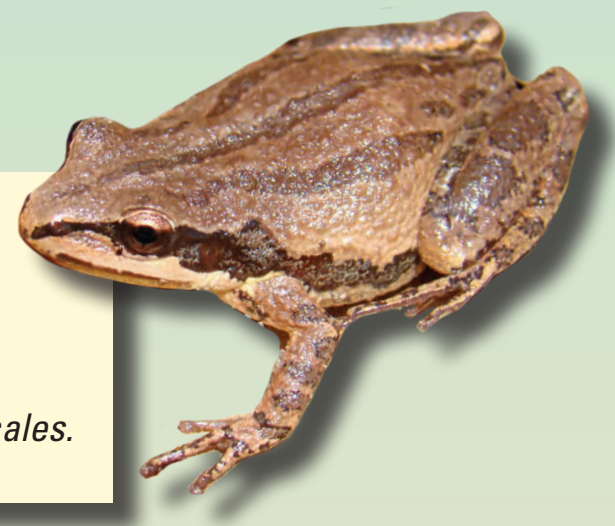

\section{News}

Welcome to the inaugural issue of ARMI's Annual Update. This update provides highlights and significant milestones of this innovative program. ARMI is uniquely qualified to provide research and monitoring results that are scalable from local to national levels, and are useful to resource managers. ARMI has produced nearly 400 peer-reviewed publications, including 18 in 2011. Some of those publications are highlighted in this fact sheet. ARMI also has a new website (armi.usgs.gov). You can now use it to explore an up-to-date list of ARMI products, to find summaries of research topics, to search for ARMI activities in your area, and to obtain amphibian photographs. ARMI's annual meeting was organized by Walt Sadinski, Upper Midwest Environmental Science Center, and held in St Louis, Missouri. We met with local scientists and managers in herpetology and were given a tour of the herpetology collection at the St. Louis Zoo.

\section{National Summary Statistics}

ARMI consists of individual projects that each have their own objectives, but each project tracks two primary amphibian metrics across the country: Apex monitoring sites track abundance and Mid-Level monitoring areas track occupancy. Abundance is the number of amphibians in a population or the number of egg masses produced. Occupancy is the probability that a site is occupied by a given species and ARMI considers this to be the most meaningful metric of amphibian status. The monitoring projects that produce these metrics each have their own methods and goals, but we are able to compare trends among sites and over time.

As of 2011, ARMI had accumulated 635 estimates of occupancy for 118 time series (a time series is a temporal sequence of occupancy estimates for a species at a monitoring area). Each of these estimates applies to a defined area of inference that typically covers 10 s to 100 s of potential amphibian habitat units. Each project requires multiple surveys of a subset of units within the area of inference so that the probability of detecting a species that is present can be incorporated into an estimate of occupancy. ARMI has 39 monitoring areas across the United States that produce occupancy estimates for 50 species of amphibian. Time series range from 2 to 9 years. These data represent the most comprehensive and quantitative data on amphibian trends in the United States.

Although the primary objective of ARMI is to provide information for DOI resource managers at a local scale, ARMI data are a unique resource in the ongoing global assessment of amphibian decline. ARMI estimates that the probability of site occupancy for the amphibians monitored has declined 4.5 percent $(95$ percent $C I=1.2-8.0$ ) annually since 2002 .

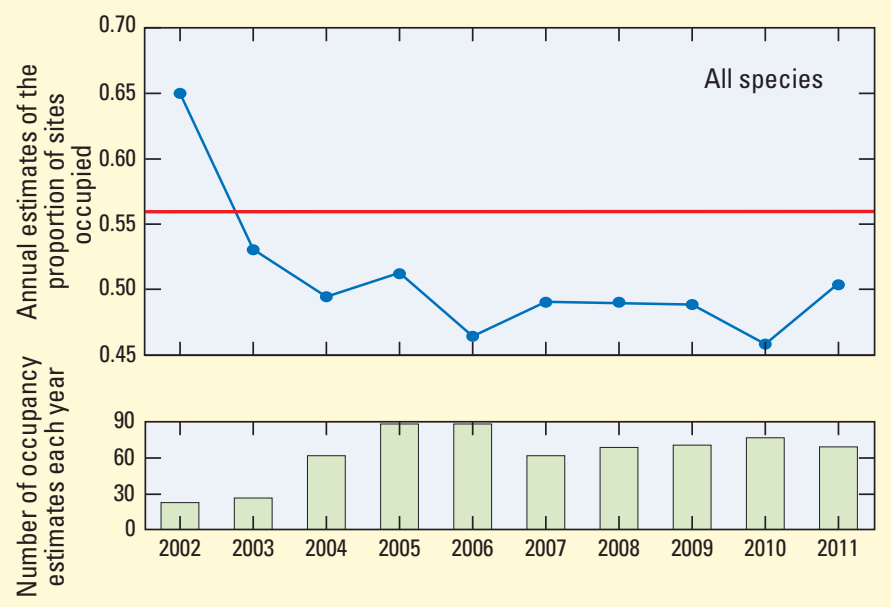

Annual estimates of the proportion of sites occupied for all amphibians at ARMI Mid-Level monitoring areas. The bar graph shows the number of occupancy estimates each year. The red line is the average proportion of sites occupied for the first three years (2002-04). 
The individual trends are variable, but 61.8 percent $(73$ of 118 time series) show a declining trend. The species and places monitored were selected for reasons related to local objectives and do not necessarily represent other species and places. In some cases, species were selected for study because of conservation concerns, but ARMI scientists often monitor a suite of species that occur in a particular habitat. We note that ARMI began after some of the severe declines in the United States are thought to have occurred.

\section{Project Updates}

\section{Invasive Species Effects in Oregon}

The Willamette Valley Mid-Level monitoring area was established in 2004 in cooperation with the U.S. Fish and Wildlife Service and the Bureau of Land Management. The primary objective is to determine how occupancy dynamics relate to introduced predators on DOI lands in the Willamette Valley. The project tracks the occupancy of five native and one introduced amphibian.

In 2011, ARMI scientists published a paper that focused on the Northern Red-legged Frog (Rana aurora). Non-native fish and American Bullfrogs (Lithobates catesbeianus) are frequently cited as contributing to the decline of native ranid frogs in the western United States. They hypothesized that non-native species, habitat, or a combination of these relate to the probability of local extinction for Northern Red-legged Frogs (Rana aurora) in Oregon. They also hypothesized that the probability of colonization relates to land use, wetland size, or riparian forest. The 5-year study found no support for the hypothesis that non-native species affect Northern Red-legged Frogs. Instead, probability of local extinction decreased with the extent of emergent vegetation and riparian forest. This finding suggests that managers consider the role of habitat when confronting non-native species problems.

Adams, M.J., Pearl, C.A., Galvan, S., and McCreary, B., 2011,

Non-native species impacts on pond occupancy by an anuran: Journal of Wildlife Management, v. 75, p. 30-35.

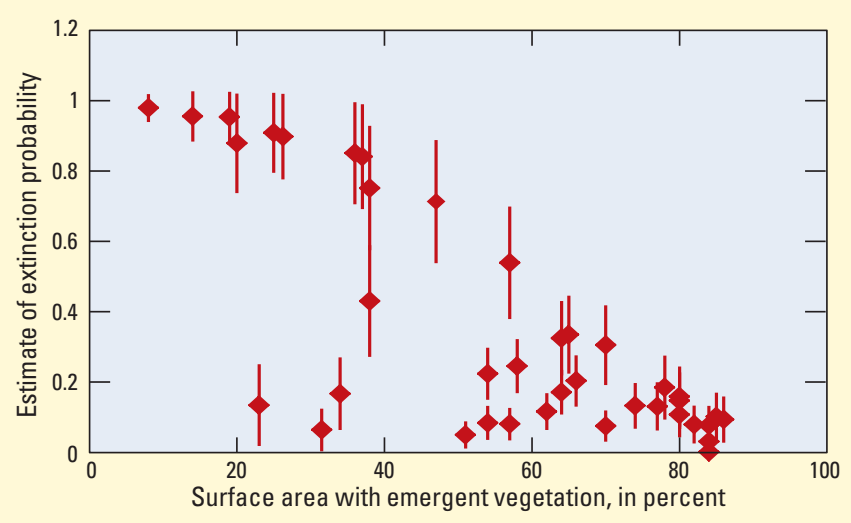

Estimated probability of local extinction at the scale of wetlands for Northern Red-legged Frogs on Department of the Interior lands in the Willamette Valley, Oregon. Estimates are based on data collected from 2004 to 2008.

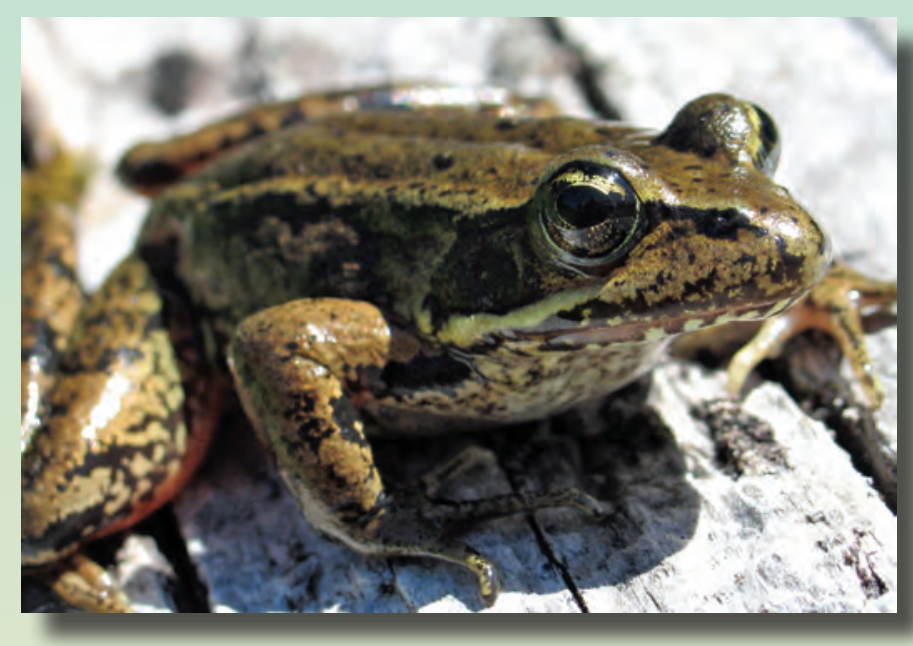

Northern Red-legged Frog. Photograph by B. McCreary, U.S. Geological Survey.

\section{Solving Statistical Challenges in Monitoring Amphibian Populations}

There are many sampling and statistical challenges to evaluating the effects of management actions on a community of often cryptic and occasionally rare species. ARMI scientists developed an extension of a single species occupancy model to estimate simultaneously, temporal changes in probabilities of occupancy, detection, colonization, extinction, and species turnover in an assemblage of ecologically similar species. The occupancy dynamics of 12 amphibian species monitored in the Lower Mississippi Alluvial Valley of Louisiana from 2002 to 2006 were modeled. All but two of the species demonstrated decreasing patterns in estimates of occurrence probabilities over the course of the 5-year study. The patterns of change in occupancy varied from those species that exhibited gradual declines to those that showed abrupt declines in occupancy between successive years.

This multi-species model allows investigators to borrow information on detection probabilities across species, thereby improving precision. Moreover, by exploring how extinction and colonization may influence change in occupancy, this approach helps reveal the relative importance of each of these vital rates to the dynamics of species within communities. This work demonstrates how the flexibility and utility of occupancy models makes them a valuable tool for asking different kinds of questions that are relevant to resource managers.

Walls, S.C., Waddle, J.H., and Dorazio, R.M., 2011, Estimating occupancy dynamics in an anuran assemblage from Louisiana, USA: Journal of Wildlife Management, v. 75, p. 751761.

\section{Population Dynamics and Disease}

Surveys in the Rocky Mountain region led to the identification of several sites that have become important Apex-level research sites, based on collaborations with the Bridger-Teton National Forest and the Colorado Natural Heritage Program. ARMI scientists used data collected at two of these sites, one in Wyoming, and the other in Colorado, to assess the effects of disease on boreal toads. The primary 
research objectives were to model population parameters, such as survival and recruitment, and compare populations where disease was present to populations that were disease-free. Results suggested that the relationship between survival and recruitment may be compensatory in the target population, and provided evidence that populations with disease are not necessarily doomed to extinction. These results highlighted the need to increase our understanding of factors that regulate animal population dynamics in the light of recent, observed declines in wildlife populations worldwide. Reliable estimates of population characteristics are critical for addressing basic and applied ecological questions and understanding the response of populations to perturbations such as disease, habitat loss, and climate change. All factors contributing to the response of the target population must be estimated to assess fully the effects of perturbation on population dynamics. A better understanding of these interactions may help to explain population regulation and predict persistence for wildlife threatened with disease. Further, reliable estimates of population parameters, such as recruitment and survival, can guide implementation of conservation actions such as repatriations or habitat management aimed to improve recruitment.

Muths, E., Scherer, R., and Pilliod, D., 2011, Compensatory effects of recruitment and survival when amphibian populations are perturbed by disease: Journal of Applied Ecology, v. 48 , p. $873-879$.

\section{Did You Hear That Right?}

Many frog and toad surveys rely on auditory detections of calling individuals to determine where species are and are not present, including the volunteer-based USGS North American Amphibian Monitoring Program and some ARMI monitoring projects. To ensure that accurate conclusions are made from survey data, it is important to reduce errors from auditory surveys and to account for observational uncertainty when estimating trends. Although methods to account for missed detections (a species is present but not recorded) are well developed, less attention has been given to false positive errors (a species is not present but recorded).

Two recent experiments conducted by ARMI researchers highlight the need to account for false-positive errors when interpreting survey results. They used an automated broadcast system to simulate typical conditions for call surveys (Frog Radio). Thirty-six observers who are involved with monitoring frogs and toads participated in the Frog Radio experiments, logging more than 100,000 observations. Even the most experienced observers made a significant number of falsepositive errors when recording observations under typical field conditions that include multiple calling species, background noise, and repeated observations. Overall, 5-8 percent of recorded observations were for species that were not actually simulated.

False-positive errors are a significant component of many ecological data sets, not only auditory surveys. Error rates such as those observed during the Frog Radio experiment, can lead to severe biases in conclusions about ecological systems if they are not accounted for. This motivated the development of statistical methods to account for false positive errors when estimating trends in species occurrence. ARMI scientists and collaborators built on existing methods that account for missed detections to deal with both error types. They demonstrated the new methods using call survey and visual encounter data for frogs and toads in and around the Chesapeake and Ohio Canal National Historic Park in the eastern United States.

Miller, D.A., Nichols, J.D., McClintock, B.T., Grant, E.H.C., Bailey, L.L., and Weir, L.A., 2011, Improving occupancy estimation when two types of observational error occur: non-detection and species misidentification: Ecology, v. 92, p. 1422-1428.

\section{Background}

ARMI resulted from the first multidisciplinary funding request in USGS, and remains a leading example of what can be achieved by applying the broad expertise and geographic scope of the USGS to high-priority resource challenges. Since its initiation in 2000, ARMI has built an unprecedented national data set on amphibians. ARMI is a national research and monitoring program that is modular, meaning it is composed of a series of monitoring projects each designed to meet objectives that are determined locally. These monitoring studies are carried out by 13 USGS ecological and water science centers, distributed across all regions of the lower 48 states. Each project complies with national guidelines, developed collaboratively among ARMI investigators, to facilitate broad synthesis at regional and national scales. This modular framework is novel for a national program and is a key feature that allows ARMI to collaborate with resource managers and meet their information needs. It also allows non-standardized methods to produce comparable data that can be scaled up. Data collected by ARMI provide the only large-scale quantitative information on amphibian decline and have led to nearly 400 peer-reviewed publications. Although much has been learned, declines have not abated, and the interactions among the various threats to amphibians are complex. Destruction of habitat remains a

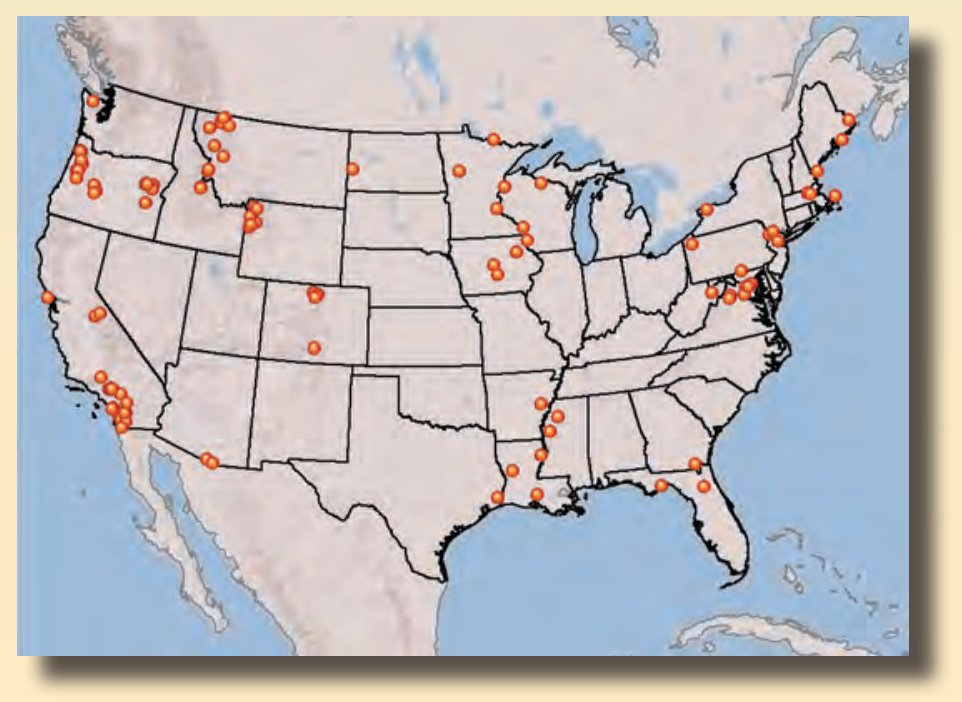

ARMI Apex and Mid-Level monitoring sites. Factors related to population dynamics are studied at Apex monitoring sites. Factors related to site occupancy dynamics are studied at Mid-Level monitoring areas. 
primary cause, but other factors, such as emerging infectious disease and invasive species, are also having serious effects on populations. Amphibian decline is a problem of local, national, and international scope that can affect ecosystem function, diversity, and commerce. To stem or reverse these declines, DOI managers and other partners need scientifically sound information at local, regional, and national scales. ARMI's modular approach is designed specifically to meet these multiscale needs. By working with land managers at a local level, ARMI investigators can design projects that address site-specific questions and use methods best suited to local conditions.

ARMI's close relationship with on-the-ground managers ensures that information needs are understood thoroughly, and results in significant leveraging of funding and resources. By following ARMI guidelines for developing population parameter estimates, these diverse and locally responsive investigations also support analyses of regional and national trends and other broad-scale questions of importance to conservation partners.

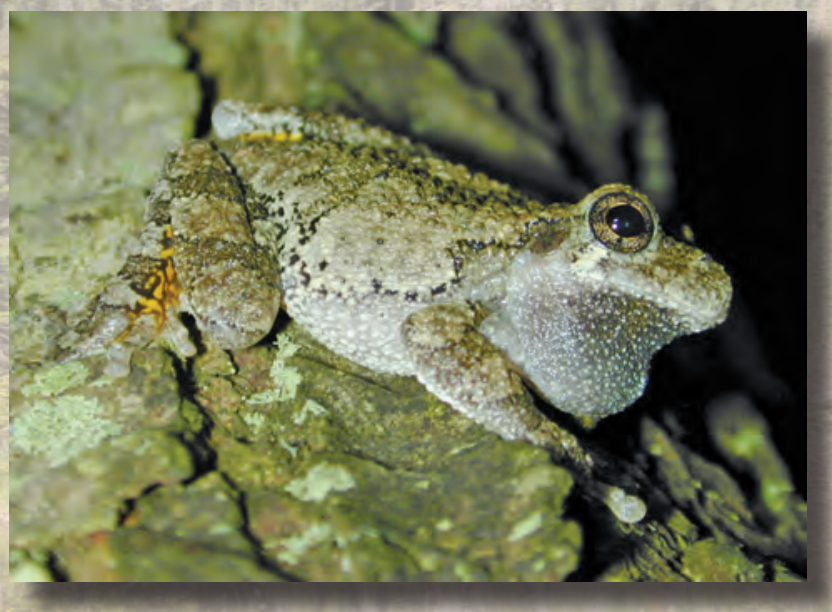

Grey Treefrog calling. Photograph by I. Chellman, U. S. Geological Survey.

\section{Frequently Asked Questions}

Are amphibians declining?

Yes, overwhelming evidence shows that the abundance or geographical distribution of many species has been recently reduced.

\section{How do we know amphibians are declining?}

Direct observations, estimates, and expert opinion are used to assess the global and national status of amphibians.

\section{Why are amphibians declining?}

There is not one single cause of amphibian declines. Instead, a combination of habitat loss, disease, invasive species, contaminants, and perhaps other threats have combined to create the current declines.

\section{Why should we care if amphibians are declining?} Amphibians play important roles in ecosystems, human health, and commerce. They have social value as symbols in some cultures, and represent an ancient source of biodiversity.

\section{What do the ARMI data tell us that other programs do not?}

The primary value of ARMI data is to answer local resource management questions. These local projects form the only national monitoring network and the only network with quantitative estimates of occupancy and abundance produced using statistically unbiased estimators. This means that ARMI provides an unusually rigorous picture of amphibian status for a long list of species and places.

How does ARMI contribute to amphibian conservation? ARMI provides reliable and relevant information to help guide management decisions by relating trends to drivers and emphasizing direct information exchange with resource managers. ARMI produces a range of information products including numerous peer-reviewed journal articles that facilitate the incorporation of amphibian concerns into resource management plans.

\section{ARMI Principles}

- Treat monitoring as research.

- Maintain the flexibility to tailor projects to local needs.

- Focus on statistically unbiased metrics that can be scaled up to achieve broader synthesis.

Authors: M.J. Adams, E. Muths, E.H.C. Grant, D.A. Miller, J.H. Waddle, S.C. Walls, L.C. Ball

Front page photographs: Bridger-Teton National Forest, by P.S. Corn, U.S. Geological Survey; Cajun Chorus Frog, by B. Glorioso, U.S. Geological Survey.

Back page photographs: Spruce Lake in Rocky Mountain National Park, by J. Bosch, Museo Nacional de Ciencias Naturales, Madrid, Spain; Red Spotted Newt, Georgia, by A. Cressler, U.S. Geological Survey.

\section{For Additional Information Contact:}

Lianne Ball, Ph.D., National Coordinator - ARMI

U.S. Geological Survey Headquarters

12201 Sunrise Valley Dr.

Reston, VA 20192

http://armi.usgs.gov

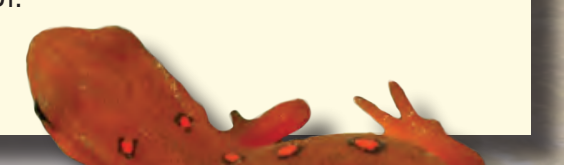

